\title{
BIO-SAFETY OF MILK PRODUCTS AND Mycobacterium avium SUBSPECIES paratuberculosis AS MAJOR MICROBIAL CONTAMINANT USING MULTIPLE TESTS INCLUDING CULTURE AND SYBR GREEN REAL-TIME ASSAY
}

\author{
Manju Singh ${ }^{1,2}$, Saurabh $\operatorname{Gupta}^{1}$, Kundan Kumar Chaubey ${ }^{1}$, Pravin Kumar Singh ${ }^{1}$, Vishal \\ Khandelwal ${ }^{1}$, Pradeep Choudhary ${ }^{1}$, Gaurav Pant ${ }^{1}$, Shoor Vir Singh ${ }^{1 *}$, Jagdip Singh Sohal ${ }^{2}$
}

\footnotetext{
${ }^{1}$ Department of Biotechnology, Institute of Applied Sciences \& Humanities, GLA University, Mathura, Uttar Pradesh, India

${ }^{2}$ Amity Institute of Microbial Technology, Amity University of Rajasthan, Jaipur, 303002, Rajasthan India
}

Received - May 11, 2020; Revision - July 20, 2020; Accepted - August 07, 2020

Available Online - August 25, 2020

DOI: http://dx.doi.org/10.18006/2020.8(4).508.523

\section{KEYWORDS}

Dot-ELISA

Indigenous ELISA kit

Indirect fluorescent antibody test

Latex agglutination test

Mycobacterium avium subspecies paratuberculosis

\section{ABSTRACT}

Twelve types of milk products belonging to 22 market brands were purchased from local shops in South Uttar Pradesh and were screened for the presence of Mycobacterium avium subspecies paratuberculosis (MAP) as major contaminant using six tests (microscopy, Indirect Fluorescent Antibody Test, IS900 PCR, Indigenous Enzyme linked Immuno Sorbent Assay, dot_ELISA, and Latex agglutination Test). Sample positive in any one of the six tests was considered as positive. Of 276 milk products screened, the cumulative bio-presence of MAP was, 52.8\% (146) and was highest in butter (75.0\%), followed by curd (66.0\%), buttermilk (52.9\%), lassi (50.0\%), cheese (40.0\%) and ice-cream (28.5\%). Bio-typing of MAP DNA from milk products using IS1311 PCR_REA revealed presence of 'Indian Bison Type' as a major biotype. Kappa $(0.700-0.815)$ and two-tailed $\mathrm{p}(<0.0001-1.0)$ values for six tests were significant for all six tests. This study for the first time revealed large scale contamination of 'milk products' marketed by leading commercial brands in India, with MAP bacilli and therefore not safe for human consumption.
* Corresponding author

E-mail: shoorvir.singh@gla.ac.in; shoorvir_singh@rediffmail.com (Dr. Shoor Vir Singh)

Peer review under responsibility of Journal of Experimental Biology and Agricultural Sciences.

Production and Hosting by Horizon Publisher India [HPI] (http://www.horizonpublisherindia.in/).

All rights reserved.
All the articles published by Journal of Experimental Biology and Agricultural Sciences are licensed under a Creative Commons Attribution-NonCommercial 4.0 International License Based on a work at www.jebas.org.

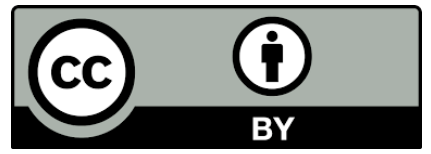




\section{Introduction}

Mycobacterium avium subspecies paratuberculosis (MAP) is the major milk contaminant and is endemic in the domestic livestock population of the country (Singh et al., 2014a; Chaubey et al., 2017) and also globally (Geraghty et al., 2014). Recently, MAP the cause of Johne's disease (JD) in animals has been associated with Crohn's (CD) and other auto-immune disorders in human beings (Singh et al., 2008; Naser et al., 2014; Banche et al., 2015). Johne's disease harms farm economics, low per animal productivity (Shephard et al., 2016; Cho et al., 2012), a serious threat to public health (Singh et al., 2016d), high costs of disease management (Johnson-Ifearulundu et al., 1999), reduced milk production, increased mortality and culling rates (Raizman et al., 2009), the in-utero transmission of MAP (Whittington \& Windsor, 2009) and reduced average weaning weight of calves (Bhattarai et al., 2013) leading to huge losses in the dairy industry.

Recently, 'food safety' has become a major concern. Therefore, milk and milk products received maximum attention as a potential source of MAP. In India, studies have limited on the bio-presence of MAP in the milk of cows (Sharma et al., 2008), goats (Singh \& Vihan, 2004), in commercial milk (Singh et al., 2009; Raghuvanshi et al., 2010) and milk products (Singh et al., 2018; Shankar et al., 2010). Pasteurization and spray drying used in making of cheese (Faria et al., 2014), powdered infant formula/calf milk replacers (Botsaris et al., 2016; Acharya et al., 2017), yogurt (Cirone et al., 2013), sour cream, and curd (Klanicova et al., 2012; Messelhausser et al., 2012) are unable to kill MAP and viable bacilli have been recovered (Sharma et al., 2008). Pasteurization norms of heating milk to $72^{\circ} \mathrm{C}$ with a holding time of $15 \mathrm{sec}$ are insufficient to inactivate MAP bacilli. MAP forms clump on heating due to high lipid contents (Mullan, 2015). High bio-presence in raw milk has also been reported by Grant (2006) and Hammer et al. (2006) in the United Kingdom (UK).

Long incubation (4-6 months) and decontamination are major constraints in the culture of MAP (Singh et al., 2007). Molecular methods (IS900 PCR, Real-time PCR, and f57 quantitative PCR) have frequently been used for rapid detection of MAP with high sensitivity in powdered infant formula (Hruska et al., 2011; Botsaris et al., 2016; Acharya et al., 2017), cheese (Faria et al., 2014), dairy products like yogurt, sour cream, and curd (Klanicova et al., 2012; Messelhausser et al., 2012; Cirone et al., 2013).

Both traditional (Indigenous Enzyme linked Immuno Sorbent Assay Kit (i_ELISA), microscopy and IS900 PCR) and recently standardized tests (dot-ELISA (d_ELISA), indirect Fluorescent antibody (i_FAT) and Latex Agglutination (LAT)) were used for the detection of MAP (Singh et al., 2016a; Singh et al., 2016b; Singh et al., 2016c) in milk products (Raghuvanshi et al., 2014; Stephen et al., 2016). Information on the bio-presence of MAP in commercially marketed 'milk products' is extremely limited in the country (Sharma et al., 2008; Raghuvanshi et al., 2014; Stephen et al., 2016). Therefore, the present study aimed to estimate the biopresence of Mycobacterium avium subspecies paratuberculosis (MAP) infection as the major microbial contamination of milk products sold in the Indian markets by the major commercial market brands in India in Indian market using multiple tests \{microscopy, serological (i_ELISA, d_ELISA, LAT), molecular (IS900 PCR), i_FAT and culture .

\section{MATERIALS AND METHODS}

\subsection{Profile of milk products}

Samples (276) of 12 types of milk products (Curd, Buttermilk, Ice cream, Lassi, Butter, Cheese, MatkaKulfi, Cream, Coffee milkshakes, Fruit Yoghurt, Makhana Kheer and Rabdi) made from pasteurized milk were purchased from local markets in Mathura (Farah and Kosi) and Agra districts of North India from 2015 to 2017. Milk products were driven from 22 leading commercial market brands (Table 1). Distribution of 276 milk products purchased for screening was: 36.2 (100), 26.0 (72), 15.2 (42), 7.2 (20), 5.8\% (16), 3.6 (10) and 1.4\% (4) of curd, buttermilk, icecream, lassi, butter, cheese, and Matka kulfi, respectively (Table 1). Milk products were of two types: (i) 'Large sample sized' $\{$ Curd (100), Buttermilk (72) and Ice cream (42)\} and (ii) 'Small sample sized' \{Lassi (20), Butter (16), Cheese (10), MatkaKulfi (4), Cream (4), Coffee milkshakes (2), Fruit Yoghurt, (2), Makhana Kheer (2), Rabdi (2)\}.

\subsection{Screening methods}

Cheese (2.0 gm) was finely grounded in $10-12 \mathrm{ml}$ of autoclaved distilled water and a homogenized solution was used as a 'test sample'. Curd, buttermilk, milkshakes, kheer, yogurt, lassi, rabari, and kulfi were used directly as 'test sample'. Ice-creams were melted at room temperature and the melted liquid was used as 'test sample'. Using tests like Microscopy, IS900 PCR, i_FAT we targeted bacilli, and using ELISA, d_ELISA, LAT, MAP lactoglobulin were targeted in the milk products.

\subsubsection{Microscopy}

Microscopy was performed as per Singh et al. (2018). The presence of short acid-fast pink staining rods will be taken as positive (Figure 1).

\subsubsection{Indirect Fluorescent antibody test}

Indirect Fluorescent antibody test (i_FAT) developed for tissues (D'Haese et al., 2005), was modified for milk samples (Singh et al., 2016b). Positive samples exhibiting green fluorescence were considered positive (Figure 2). 
Table 1 Comparative evaluation of six, five, four, three, two and one tests combinations for the screening of Mycobacterium avium subsp. paratuberculosis infection in milk products

\begin{tabular}{|c|c|c|c|c|c|c|c|c|c|c|c|c|c|c|c|c|c|c|c|}
\hline \multirow{2}{*}{ Tests (Samples) } & \multicolumn{18}{|c|}{ Six tests combinations - $\%(n)$, } & \multirow{2}{*}{ Positives $\%(n)$} \\
\hline & 1 & 2 & 3 & 4 & 5 & 6 & 7 & 8 & 9 & 10 & 11 & 12 & 13 & 14 & 15 & 16 & 17 & 18 & \\
\hline 1. Microscopy & + & - & + & + & + & + & - & - & + & - & - & - & + & + & + & + & - & - & $41.3(114)$ \\
\hline 2. i_FAT & + & - & + & + & + & + & + & + & + & - & + & - & + & - & - & - & + & - & $39.8(110)$ \\
\hline 3. IS900 PCR & + & - & - & + & - & - & - & - & - & - & - & - & - & + & - & - & - & - & $7.9(22)$ \\
\hline 4. i_ELISA & + & - & + & - & - & + & + & - & - & + & - & + & - & - & - & - & - & - & $22.4(62)$ \\
\hline 5. d_ELISA & + & - & + & + & + & + & + & + & + & + & + & + & - & - & + & - & - & + & $33.3(92)$ \\
\hline 6. LAT & + & - & + & + & + & - & + & + & - & + & - & - & - & - & - & - & - & - & $23.1(64)$ \\
\hline \multirow{3}{*}{$\begin{array}{c}\text { Total- } n \\
\text { (276) \% }\end{array}$} & 14 & 130 & 30 & 6 & 2 & 6 & 6 & 2 & 8 & 4 & 2 & 2 & 26 & 2 & 2 & 18 & 8 & 8 & \multirow{3}{*}{$52.8(146)$} \\
\hline & \multirow{2}{*}{5.0} & \multirow{2}{*}{47.1} & \multicolumn{2}{|c|}{13.0} & & 5.0 & & \multicolumn{3}{|c|}{5.0} & & & 12.3 & & & \multirow{2}{*}{\multicolumn{2}{|c|}{$\begin{array}{l}12.3 \\
(34)\end{array}$}} & & \\
\hline & & & \multicolumn{13}{|c|}{$35.5(98)$} & & & & \\
\hline
\end{tabular}

Total samples n-276; (-): Denotes the negative samples in an individual test of that particular test combination; (+): Denotes the positive samples in an individual test of that particular test combination; 1-18: Maximum permutation and combinations possible in 6 test regimen; Total-n: Represents only total positive samples in that particular test combination.

(A)

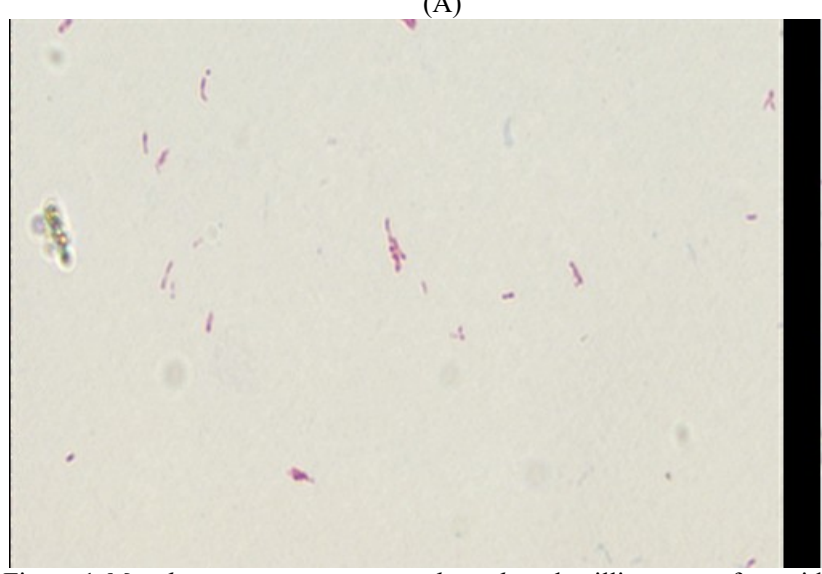

(B)

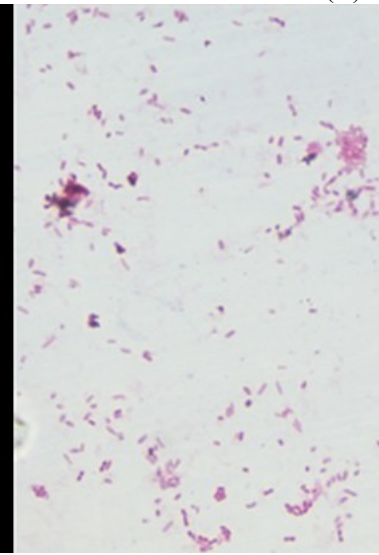

Figure 1 Mycobacterium avium paratuberculosis bacilli as seen after acid-fast staining in (A) commercial milk product; (B) positive control

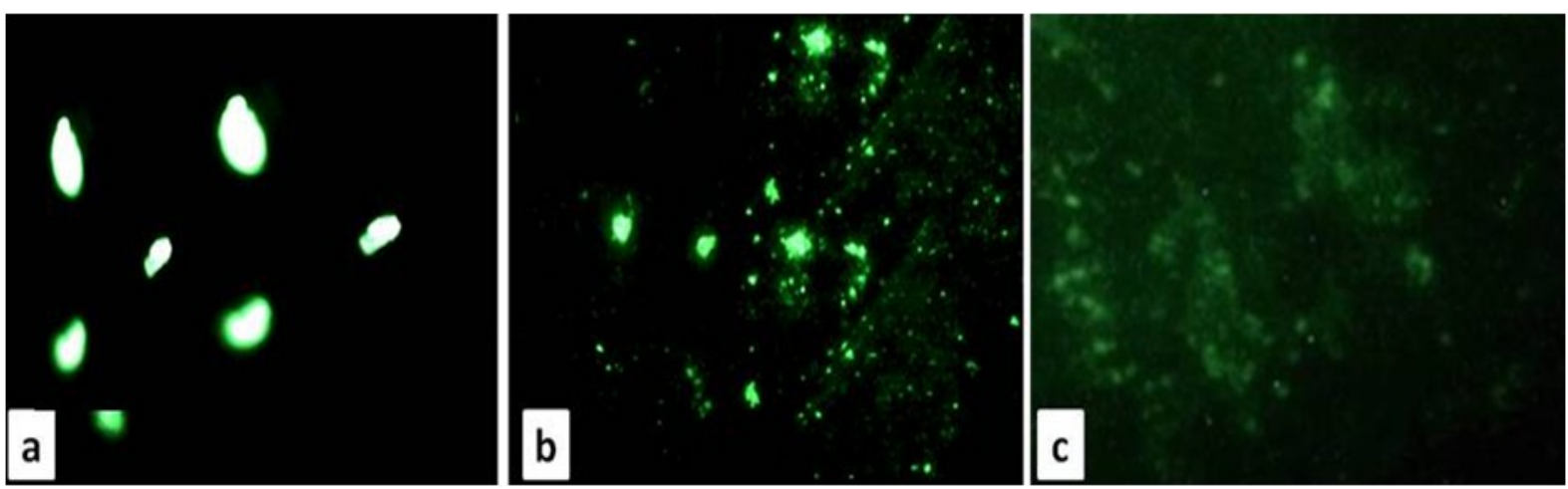

Figure 2 Green fluorescence indicates the presence of Mycobacterium avium paratuberculosis bacilli by indirect fluorescent antibody test; a positive control; b: commercial milk product; c: negative control

Journal of Experimental Biology and Agricultural Sciences http://www.jebas.org 


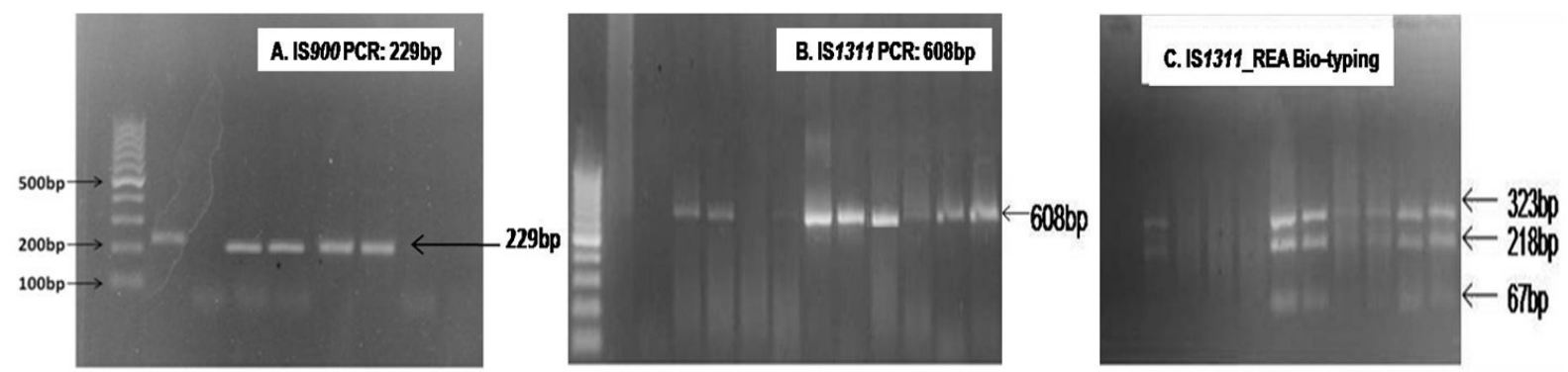

Figure 3 Agarose gel electrophoresis of amplicons obtained by IS900 assay(A) performed on commercial milk products; molecular characterization of IS900 positive Mycobacterium avium paratuberculosis Deoxyribonucleic acid by IS1311assay(B) and IS1311_Restriction Enzyme analysis (C)
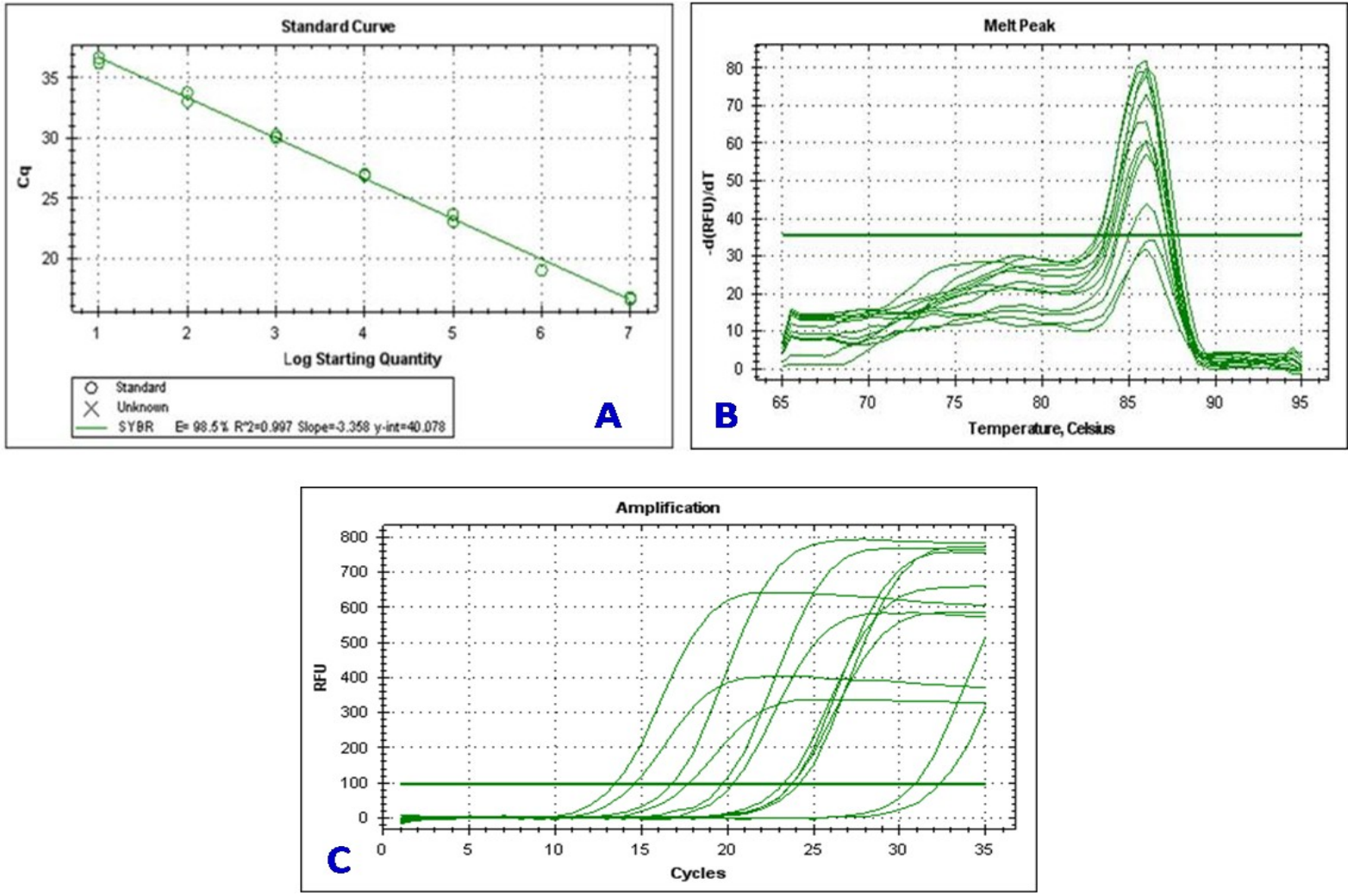

Figure 4 Real time assay for the quantitative detection of Mycobacterium avium paratuberculosis bacilli $\{$ A: Standard curve generated by graphing the $\log$ of the Deoxyribonucleic acid concentration (serial dilutions from 0 to $10^{5}$ folds) of Mycobacterium avium paratuberculosis Deoxyribonucleic acid $(10 \mathrm{ng} / \mu \mathrm{L})$ vs. the $\mathrm{CT}$ value showing 98.5 efficiencies $\left(\mathrm{R}^{2}=0.997\right)$ for detection of Mycobacterium avium paratuberculosis; $\mathrm{B}$ : Melting peak of IS900 amplification product for tested Mycobacterium avium paratuberculosis Deoxyribonucleic acid samples; C: Amplification plot of milk products showing positive for the Mycobacterium avium paratuberculosis Deoxyribonucleic acid using Real Time assay based assay targeting IS 900 gene\}

\subsubsection{Deoxyribonucleic acid isolation}

Commercial milk product's DNA was isolated as per van Soolingen et al. (1991) with some modifications (Singh et al., 2018).

\subsubsection{IS900 Polymerase Chain Reaction}

Isolated DNA was amplified by specific IS900 PCR (Singh et al., 2008) using Vary et al. (1990) primers. The yield of a specific PCR product (229 bp) will be taken as positive (Figure 3).

\subsubsection{IS1311 assay and restriction endonuclease analysis}

IS900 PCR positive DNA samples were subjected to bio-typing using M56 and M119 primers (Sevilla et al., 2005) (Figure 3).

\subsubsection{SYBR Green Real Time assay Targeting IS900 Gene}

MAP DNA from milk products $(\mathrm{n}=34)$ was screened by IS 900 SYBR green Real time PCR (SYBR RT_PCR) following the Gupta et al. (2017) protocol (Figure 4). 


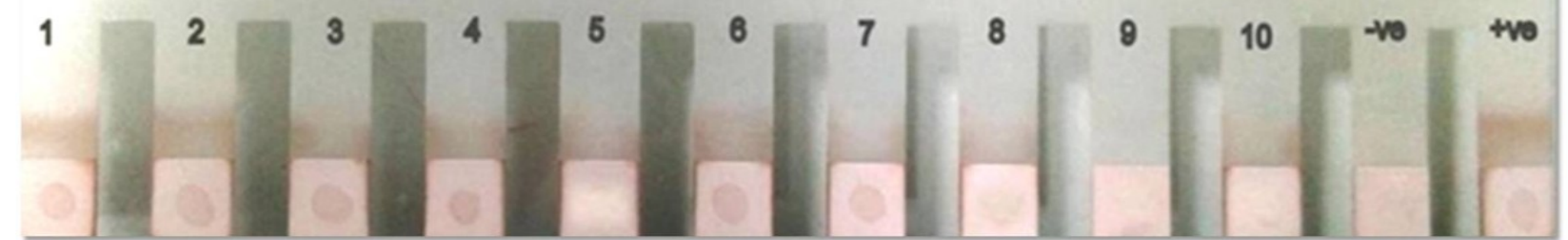

Figure 5 Dot-Enzyme Linked Immuno Sorbent Assay of commercial milk products (1-10) showing the presence of Mycobacterium avium paratuberculosis antibodies as a positive brown dot; +ve: positive control (brown dot); -ve: negative control (no brown dot)

1

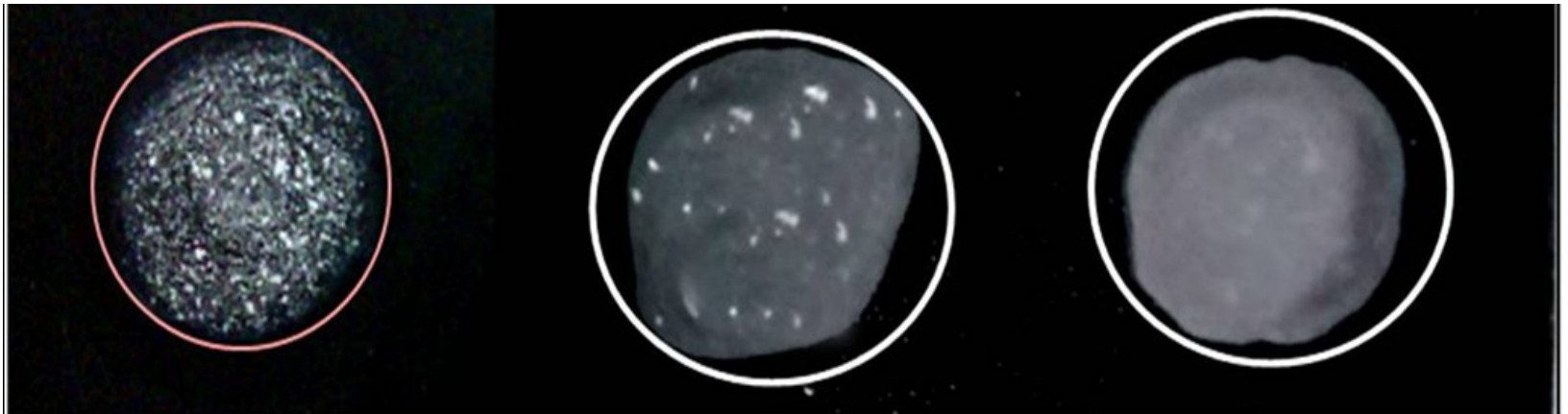

Figure 6 Latex agglutination test result for the detection of Mycobacterium avium paratuberculosis antibodies in commercial milk products (1: Milk positive control; 2: Positive commercial milk product; 3: Negative commercial milk product)

\subsubsection{Culture}

IS1311PCR positive samples were cultured as per Merkal \& Richards (1972) and tubes screened at weekly intervals for the appearance of typical MAP colonies (Singh \& Vihan, 2004).

\subsubsection{Indigenous Enzyme Linked Immuno Sorbent Assay kit}

Milk-based indigenous ELISA' kit (Singh et al., 2007) used for screening with modifications (Singh et al., 2018). OD values were expressed as sample-to-positive (S/P) ratios as per Collins (2002). Sample in low positive (LP), positive (P), and strong positive (SP) categories were considered positive for MAP infection.

\subsubsection{Dot-Enzyme Linked Immuno Sorbent Assay}

Dot-ELISA was performed as per Singh et al. (2016a) (Figure 5).

\subsubsection{Latex Agglutination test}

The Latex Agglutination test (LAT) was performed as per the method of Singh et al. (2016c) and positive results were noted within 2 min (Figure 6).

\subsection{Statistical analysis}

Statistical significance was measured between two tests, McNemar's test and Kappa agreement statistical analysis methods applied by Graph Pad software, California, United States of America (USA). Sensitivity and specificity were measured by Med-Calc software, Acacialaan 228400 Ostend, Belgium.

\section{Results}

Samples from Cream (4), Coffee milkshakes (2), Fruit Yoghurt (2), MakhanaKheer (2), Rabdi (2) were negative in all diagnostic tests performed. Of 276 milk products screened, cumulative bio-presence was $52.8 \%$ (146) by six tests (Table 1). Product-wise, bio-presence of MAP was the highest in butter (75.0\%), followed by curd (66.0\%), buttermilk (52.9\%), lassi $(50.0 \%)$, cheese $(40.0 \%)$ and icecream $(28.5 \%)$. The sensitivity of the test for the detection of biopresence of MAP was, 41.3 (114), 39.8 (110), 33.3 (92), 23.1 (64), 22.4 (62) and $7.9 \%$ (22) in microscopy, i_FAT, dot_ELISA, LAT, i_ELISA and IS900 PCR, respectively. None of the $47.1 \%$ (130) milk products (perfect negative) were detected by any of the six tests (Table 1). Samples (22) positive in IS900 PCR were bio-typed and 
bio-typing of seven types of milk products revealed the presence of 'Indian Bison Type' biotype in $5.7 \%$ (16) in five milk products (curd, buttermilk, ice-cream, butter, and cheese) (Table 2).

\subsection{Large sample-sized milk products}

\subsubsection{Curd}

The Bio-presence of MAP was very high $(66.0 \%)$ in curd samples (100) of 14 brands. The 50.0, 40.0, and 6.0\% samples were found to be positive for the bio-presence of MAP using microscopy, i_FAT and IS900 PCR (antigen detection), and $34.0,44.0$ and $34.0 \%$ in i_ELISA, d_ELISA and LAT (antibody detection) tests, respectively. The $6.0,18.0,6.0,6.0,8.0$, and $20.0 \%$, samples were positive in six, five, four, three, two, and one test, respectively (Table 3 ). Microscopy was most sensitive followed by d_ELISA, i_FAT, i_ELISA, LAT, and IS 900 PCR. Except, Namaste India and Nestle, the rest of 14 market brands, $85.7 \%$ (12) were positive and bio-presence was 76.9 and $46.1 \%$ in Mother dairy and Amul brands, respectively (Table 4). Biotyping of $46.1 \%$ positive of Amul revealed $7.6 \%$ were 'Indian Bison Type'.

\subsubsection{Buttermilk}

Buttermilk from eight brands was next largest sample $\{37.5 \%$ ( $n$ 72 ) $\}$ and $50.0 \%$ were positive (Table 2). Bio-presence was 52.9, 28.5, and $50.0 \%$ in Amul, Mother Dairy, and Ananda brands, respectively (Table 4). All samples from Namaste India (4), Parag (2), and Sanchi dairy (2) were positive. Two samples each from Gyan and Payas diary were negative. The i_FAT was most sensitive (44.4\%) followed by microscopy (38.8\%), d_ELISA (33.3\%), LAT (22.2\%), i_ELISA (19.4\%), and IS900 PCR $(19.8 \%)$ for the detection of bio-presence of MAP in milk products. In all the six tests, 8.3 and $50.0 \%$ samples were positive and negative, respectively (Table 3). Except, $8.3 \%$ of samples detected by single test (microscopy, i_FAT, and d_ELISA), rest $41.6 \%$ were detected by multiple tests (two to six tests). Bio-typing of $36(50.0 \%)$ positive samples showed, $16(22.2 \%)$ were 'Indian Bison Type' where Amul (5.8\%), Mother dairy (14.2\% and Namaste India (100.0\%) (Table 4).

\subsubsection{Ice cream}

Of 42 ice-cream samples, 12 (28.5\%) were positive (Table 2). The Bio-presence of MAP was 37.5, 25.0, 33.3, and 100.0\% in Cream well, Sudha, Havmor and Say Natural brands, respectively. None of the samples from Amul, Vadilal, and Madhu brand was positive (Table 4). i_FAT was most sensitive (23.8\%) followed by microscopy (19.0\%), d_ELISA (9.5\%), and in three tests (LAT, i_ELISA, and IS900 PCR-4.7\% each). In i_FAT, $9.5 \%$ of samples were positive and $19.0 \%$ by multiple tests (two to six tests) (Table 3). Of two (4.7\%) positive icecream (Say Natural brands) in IS 900 PCR, both were 'Indian Bison Type' (Table 4).

Table 2 Test-wise bio-presence and bio-type profile of Mycobacterium avium subsp. paratuberculosis in 'commercial milk products' of leading Indian market brands

\begin{tabular}{|c|c|c|c|c|c|c|c|}
\hline \multirow{2}{*}{$\begin{array}{c}\text { Milk products } \\
n(\%)\end{array}$} & \multicolumn{6}{|c|}{ Positives $^{(\mathrm{a})} /$ Samples screened, \% (n) } & \multirow{2}{*}{ Bio-type $^{(\mathrm{b}}$} \\
\hline & Microscopy & i_FAT & IS900 PCR & i_ELISA & d_ELISA & LAT & \\
\hline 1. Curd - $100(36.2)$ & $\begin{array}{c}50.0 \\
(50 / 100)\end{array}$ & $\begin{array}{c}40.0 \\
(40 / 100)\end{array}$ & $\begin{array}{c}6.0 \\
(6 / 100)\end{array}$ & $\begin{array}{c}34.0 \\
(34 / 100)\end{array}$ & $\begin{array}{c}44.0 \\
(44 / 100)\end{array}$ & $\begin{array}{c}34.0 \\
(34 / 100)\end{array}$ & $\begin{array}{l}6.0 \\
(6)\end{array}$ \\
\hline 2. Butter milk- $72(26.0)$ & $\begin{array}{c}38.8 \\
(28 / 72)\end{array}$ & $\begin{array}{c}44.4 \\
(32 / 72)\end{array}$ & $\begin{array}{c}13.8 \\
(10 / 72)\end{array}$ & $\begin{array}{c}19.4 \\
(14 / 72)\end{array}$ & $\begin{array}{c}33.3 \\
(24 / 72)\end{array}$ & $\begin{array}{c}22.2 \\
(16 / 72)\end{array}$ & $\begin{array}{l}5.5 \\
\text { (4) }\end{array}$ \\
\hline 3. Ice cream - $42(15.2)$ & $\begin{array}{c}19.0 \\
(8 / 42)\end{array}$ & $\begin{array}{c}23.8 \\
(10 / 42)\end{array}$ & $\begin{array}{c}4.76 \\
(2 / 42)\end{array}$ & $\begin{array}{c}4.76 \\
(2 / 42)\end{array}$ & $\begin{array}{c}9.52 \\
(4 / 42)\end{array}$ & $\begin{array}{c}4.76 \\
(2 / 42)\end{array}$ & $\begin{array}{l}4.7 \\
(2)\end{array}$ \\
\hline 4. Lassi - $20(7.2)$ & $\begin{array}{c}40.0 \\
(8 / 20)\end{array}$ & $\begin{array}{c}40.0 \\
(8 / 20)\end{array}$ & $\begin{array}{c}0.0 \\
(0 / 20)\end{array}$ & $\begin{array}{c}20.0 \\
(4 / 20)\end{array}$ & $\begin{array}{c}20.0 \\
(4 / 20)\end{array}$ & $\begin{array}{c}20.0 \\
(4 / 20)\end{array}$ & 00 \\
\hline 5. Butter - $16(5.8)$ & $\begin{array}{c}87.5 \\
(14 / 16)\end{array}$ & $\begin{array}{c}87.5 \\
(14 / 16)\end{array}$ & $\begin{array}{c}12.5 \\
(2 / 16)\end{array}$ & $\begin{array}{c}37.5 \\
(6 / 16)\end{array}$ & $\begin{array}{c}75.0 \\
(12 / 16)\end{array}$ & $\begin{array}{c}25.0 \\
(4 / 16)\end{array}$ & $\begin{array}{l}12.5 \\
(2)\end{array}$ \\
\hline 6. Cheese - $10(3.6)$ & $\begin{array}{c}40.0 \\
(4 / 10)\end{array}$ & $\begin{array}{c}40.0 \\
(4 / 10)\end{array}$ & $\begin{array}{c}20.0 \\
(2 / 10)\end{array}$ & $\begin{array}{c}20.0 \\
(2 / 10)\end{array}$ & $\begin{array}{c}40.0 \\
(4 / 10)\end{array}$ & $\begin{array}{c}40.0 \\
(4 / 10)\end{array}$ & $\begin{array}{l}20.0 \\
(2)\end{array}$ \\
\hline 7. MatkaKulfi- 4 (1.4) & $\begin{array}{l}50.0 \\
(2 / 4)\end{array}$ & $\begin{array}{l}50.0 \\
(2 / 4)\end{array}$ & $\begin{array}{c}0.0 \\
(0 / 4)\end{array}$ & $\begin{array}{c}0.0 \\
(0 / 4)\end{array}$ & $\begin{array}{c}0.0 \\
(0 / 4)\end{array}$ & $\begin{array}{c}0.0 \\
(0 / 4)\end{array}$ & 00 \\
\hline Total $^{(\mathrm{c})}(276)$ & $\begin{array}{l}41.3 \\
(114)\end{array}$ & $39.8(110)$ & $\begin{array}{l}7.9 \\
(22)\end{array}$ & $\begin{array}{l}22.4 \\
(62)\end{array}$ & $\begin{array}{l}33.3 \\
(92)\end{array}$ & $\begin{array}{l}23.1 \\
(64)\end{array}$ & $\begin{array}{l}5.7 \\
(16)\end{array}$ \\
\hline
\end{tabular}

LAT: Latex Agglutination Test, i_FAT: Indirect Fluorescent Antibody Test, Cheese (fresh paneer); ${ }^{(a)}$ Positive in at least one of six tests; ${ }^{(b)}$ 'Indian Bison Type' using IS1311 PCR_REA; ${ }^{(c)}$ None of these 6 samples \{8. Cream (4), 9.Coffee milkshakes (2), 10.Fruit Yoghurt (2), 11.Makhana Kheer (2), 12. Rabdi (2)\} 
Table 3 Market brands and milk product-wise bio-presence of Mycobacterium avium subsp. paratuberculosis in six tests, combinations

\begin{tabular}{|c|c|c|c|c|c|c|c|c|}
\hline \multirow{3}{*}{ Sn } & \multicolumn{3}{|c|}{ Milk products screened $(n)$} & \multicolumn{5}{|c|}{ Positives in 'test combinations', $\%$ (positive samples) } \\
\hline & \multirow{2}{*}{ Market Brands } & \multirow{2}{*}{\multicolumn{2}{|c|}{ Sample Type }} & \multirow{2}{*}{6 tests } & \multirow{2}{*}{2 - 5 tests } & \multicolumn{3}{|c|}{ Single test $(\%)$} \\
\hline & & & & & & AFB & i_FAT & d_ELISA \\
\hline \multirow{5}{*}{1} & \multirow{5}{*}{$\begin{array}{l}\text { Mother Dairy } \\
\text { (56) }\end{array}$} & Butter milk & 14 & 00 & $28.5(4)$ & 00 & \multirow{5}{*}{00} & \multirow{5}{*}{00} \\
\hline & & Curd & 26 & 00 & $61.5(16)$ & $15.3(4)$ & & \\
\hline & & Lassi & 8 & 00 & $25.0(2)$ & \multirow{3}{*}{00} & & \\
\hline & & Paneer and Fruit yogurt & 4 & 00 & 00 & & & \\
\hline & & Butter & 4 & $50.0(2)$ & $50.0(2)$ & & & \\
\hline \multirow{6}{*}{2} & \multirow{6}{*}{$\begin{array}{l}\text { Amul } \\
(84)\end{array}$} & Butter milk & 34 & $5.8(2)$ & $29.4(10)$ & $5.8(2)$ & $5.8(2)$ & $5.8(2)$ \\
\hline & & Curd & 26 & $23.0(6)$ & $7.6(2)$ & $15.3(4)$ & 00 & 00 \\
\hline & & Butter & 8 & 00 & $75.0(6)$ & 00 & 00 & $25.0(2)$ \\
\hline & & Cheese & 4 & 00 & $100.0(4)$ & & \multirow{6}{*}{00} & \multirow{8}{*}{00} \\
\hline & & Cream and Ice cream & 8 & 00 & 00 & 00 & & \\
\hline & & Lassi & 4 & 00 & $50.0(2)$ & $50.0(2)$ & & \\
\hline \multirow{2}{*}{3} & \multirow{2}{*}{ Ananda (14) } & Butter milk & 12 & 00 & $50.0(6)$ & \multirow{3}{*}{00} & & \\
\hline & & Curd & 2 & 00 & $100.0(2)$ & & & \\
\hline 4 & Cavins(2) & Coffee milkshake & 2 & 00 & 00 & & & \\
\hline 5 & Cream well (18) & Ice cream & 16 & 00 & $12.5(2)$ & 00 & $25.0(4)$ & \\
\hline$J$ & Credint went (10) & Matkakulfi & 2 & 00 & $100.0(2)$ & 00 & 00 & \\
\hline 6 & Gonal ii (4) & Curd & 2 & 00 & 00 & 00 & 00 & $100.0(2)$ \\
\hline 0 & Goparj1 (4) & Lassi & 2 & 00 & 00 & & & \\
\hline & & Buttermilk & 2 & 00 & 00 & & & \\
\hline 7 & Gyan Dairy (12) & Curd & 10 & 00 & $60.0(6)$ & & & \\
\hline 8 & Havmor (6) & Ice cream & 6 & 00 & $33.3(2)$ & & & \\
\hline 9 & Madhu(2) & Ice cream & 2 & 00 & 00 & & & \\
\hline 10 & Madhusudan (2) & Curd & 2 & 00 & $100.0(2)$ & & & \\
\hline 11 & Mahanand (4) & Curd & 4 & 00 & $100.0(4)$ & 00 & 00 & 00 \\
\hline 12 & Namaste India ( 8 ) & Curd & 4 & 00 & 00 & & & \\
\hline 12 & Namaste India (8) & Butter milk & 4 & $100.0(4)$ & 00 & & & \\
\hline 13 & Nestle (4) & Curd & 4 & 00 & 00 & & & \\
\hline 14 & Pankaj Paneer (2) & Paneer & 2 & 00 & 00 & & & \\
\hline & & Butter milk & 2 & 00 & $100.0(2)$ & & & \\
\hline 15 & Parag Dairy(8) & Curd & 4 & 00 & $50.0(2)$ & 00 & 00 & $50.0(2)$ \\
\hline & & Lassi & 2 & 00 & $100.0(2)$ & & & \\
\hline 16 & Payas (2) & Buttermilk & 2 & 00 & 00 & & & \\
\hline & & Hung curd & 2 & 00 & $100.0(2)$ & 00 & 00 & \\
\hline 17 & Sanchi Dairy (8) & Butter milk & 2 & 00 & $100.0(2)$ & 00 & 00 & \\
\hline 17 & Sancn1 Dairy ( & Lassi & 2 & 00 & $100.0(2)$ & & & \\
\hline & & Rabdi & 2 & 00 & 00 & & & \\
\hline & & Curd & 4 & 00 & $50.0(2)$ & 00 & $50.0(2)$ & \\
\hline 18 & $\operatorname{Saras}(10)$ & Butter & 2 & 00 & $100.0(2)$ & & & \\
\hline & & Lassi and Paneer & 4 & 00 & 00 & 00 & & 00 \\
\hline 19 & Say Natural (2) & Ice cream & 2 & 00 & $100.0(2)$ & & & \\
\hline 20 & Sheer (6) & Curd & 6 & 00 & 00 & $100.0(6)$ & & \\
\hline & & Curd & 4 & 00 & $50.0(2)$ & & 00 & \\
\hline & & Ice cream & 6 & 00 & $33.3(2)$ & & & \\
\hline 21 & Sudha(16) & $\begin{array}{l}\text { Cream and } \\
\text { Makhana Kheer }\end{array}$ & 4 & 00 & 00 & 00 & & \\
\hline & & Butter & 2 & 00 & $100.0(2)$ & & & \\
\hline 22 & Vadilal(6) & Ice cream and Matkakulfi & 6 & 00 & 00 & & & \\
\hline & & otal & 276 & $5.0(14)$ & $35.5(98)$ & $6.5(18)$ & $2.8(8)$ & $2.8(8)$ \\
\hline
\end{tabular}

Journal of Experimental Biology and Agricultural Sciences http://www.jebas.org 
Table 4 Cumulative percent bio-presence' and bio-type profile of Mycobacterium avium subsp. paratuberculosis in the screening of milk products using six tests combinations

\begin{tabular}{|c|c|c|c|c|c|}
\hline \multirow[b]{2}{*}{ Sn } & \multicolumn{4}{|c|}{ Milk products (positives / screened) \% (n) } & \multirow[b]{2}{*}{ Bio-Type $^{(b)}$} \\
\hline & $\begin{array}{l}\text { Market brands, } \\
\text { Area of operation }\end{array}$ & Milk produc & & Positives $^{(a)}$ & \\
\hline \multirow{6}{*}{1} & \multirow{6}{*}{$\begin{array}{l}\text { Mother Dairy (56), } \\
\text { Delhi }\end{array}$} & Butter milk & 14 & 28.5 & 14.2 \\
\hline & & Curd & 26 & 76.9 & 00 \\
\hline & & Lassi & 8 & $25.0(2)$ & 00 \\
\hline & & Paneer & 2 & $0.0(0)$ & 00 \\
\hline & & Fruit yoghurt & 2 & $0.0(0)$ & 00 \\
\hline & & Butter & 4 & $100.0(4)$ & $50.0(2)$ \\
\hline \multirow{7}{*}{2} & \multirow{7}{*}{$\begin{array}{c}\text { Amul (84), } \\
\text { Gujrat }\end{array}$} & Butter milk & 34 & $52.9(18)$ & $5.8(2)$ \\
\hline & & Curd & 26 & $46.1(12)$ & $7.6(2)$ \\
\hline & & Butter & 8 & $100.0(8)$ & 00 \\
\hline & & Cream & 4 & $0.0(0)$ & 00 \\
\hline & & Cheese (Paneer) & 4 & $100.0(4)$ & $50.0(2)$ \\
\hline & & Ice cream & 4 & $0.0(0)$ & 00 \\
\hline & & Lassi & 4 & $100.0(4)$ & 00 \\
\hline \multirow{2}{*}{3} & \multirow{2}{*}{$\begin{array}{l}\text { Ananda (14), } \\
\text { New Delhi and } \\
\text { Uttar Pradesh }\end{array}$} & Butter milk & 12 & $50.0(6)$ & 00 \\
\hline & & Curd & 2 & $100.0(2)$ & 00 \\
\hline 4 & $\begin{array}{c}\text { Cavins (2), } \\
\text { India }\end{array}$ & Coffee milk shake & 2 & $0.0(0)$ & 00 \\
\hline \multirow{2}{*}{5} & \multirow{2}{*}{$\begin{array}{l}\text { Cream well (18), } \\
\text { India, Delhi }\end{array}$} & Ice cream & 16 & $37.5(6)$ & 00 \\
\hline & & Matka Kulfi & 2 & $100.0(2)$ & 00 \\
\hline \multirow{2}{*}{6} & \multirow{2}{*}{$\begin{array}{l}\text { Gopal ji (4), } \\
\text { Uttar Pradesh }\end{array}$} & Curd & 2 & $100.0(2)$ & 00 \\
\hline & & Lassi & 2 & $0.0(0)$ & 00 \\
\hline \multirow{2}{*}{7} & \multirow{2}{*}{$\begin{array}{l}\text { Gyan Dairy (12), } \\
\text { Lucknow }\end{array}$} & Butter milk & 2 & $0.0(0)$ & 00 \\
\hline & & Curd & 10 & $60.0(6)$ & 00 \\
\hline 8 & $\begin{array}{c}\text { Havmor(6), } \\
\text { New Delhi and Rajasthan }\end{array}$ & Ice cream & 6 & $33.3(2)$ & 00 \\
\hline 9 & $\begin{array}{c}\text { Madhu(2), } \\
\text { Agra }\end{array}$ & Ice cream & 2 & $0.0(0)$ & 00 \\
\hline 10 & $\begin{array}{l}\text { Madhusudan (2), } \\
\text { New Delhi and } \\
\text { Uttar Pradesh }\end{array}$ & Curd & 2 & $100.0(2)$ & 00 \\
\hline 11 & $\begin{array}{l}\text { Mahanand(4), } \\
\text { Maharashtra }\end{array}$ & Curd & 4 & $100.0(4)$ & 00 \\
\hline \multirow{2}{*}{12} & \multirow{2}{*}{$\begin{array}{l}\text { Namaste India (8), } \\
\text { Uttar Pradesh and Lucknow }\end{array}$} & Curd & 4 & $0.0(0)$ & 00 \\
\hline & & Butter milk & 4 & $100.0(4)$ & $100.0(4)$ \\
\hline 13 & $\begin{array}{l}\text { Nestle (4), } \\
\text { Switzerland }\end{array}$ & Curd & 4 & $0.0(0)$ & 00 \\
\hline 14 & $\begin{array}{l}\text { Pankaj Paneer (2), } \\
\text { Agra }\end{array}$ & Paneer & 2 & $0.0(0)$ & 00 \\
\hline \multirow{3}{*}{15} & \multirow{3}{*}{$\begin{array}{l}\text { Parag Dairy (8), } \\
\text { Uttar Pradesh }\end{array}$} & Butter milk & 2 & $100.0(2)$ & 00 \\
\hline & & Curd & 4 & $100.0(4)$ & 00 \\
\hline & & Lassi & 2 & $100.0(2)$ & 00 \\
\hline 16 & $\begin{array}{l}\text { Payas(2), } \\
\text { Rajasthan }\end{array}$ & Butter milk & 2 & $0.0(0)$ & 00 \\
\hline \multirow{4}{*}{17} & \multirow{4}{*}{$\begin{array}{l}\text { Sanchi Dairy (8), } \\
\text { Madhya Pradesh }\end{array}$} & Hung curd & 2 & $100.0(2)$ & 00 \\
\hline & & Butter milk & 2 & $100.0(2)$ & 00 \\
\hline & & Lassi & 2 & $100.0(2)$ & 00 \\
\hline & & Rabdi & 2 & $0(0.0)$ & 00 \\
\hline
\end{tabular}




\begin{tabular}{|c|c|c|c|c|c|}
\hline \multirow[b]{2}{*}{$\mathrm{Sn}$} & \multicolumn{4}{|c|}{ Milk products (positives / screened) $\%(n)$} & \multirow[b]{2}{*}{ Bio-Type $^{(b)}$} \\
\hline & $\begin{array}{l}\text { Market brands, } \\
\text { Area of operation }\end{array}$ & \multicolumn{2}{|c|}{ Milk products } & Positives $^{(a)}$ & \\
\hline \multirow{4}{*}{18} & \multirow{4}{*}{$\begin{array}{l}\text { Saras (10), } \\
\text { Rajasthan }\end{array}$} & Curd & 4 & $100.0(4)$ & 00 \\
\hline & & Butter & 2 & $100.0(2)$ & 00 \\
\hline & & Lassi & 2 & $0(0.0)$ & 00 \\
\hline & & Paneer & 2 & $0(0.0)$ & 00 \\
\hline 19 & $\begin{array}{c}\text { Say Natural (2), } \\
\text { India }\end{array}$ & Ice cream & 2 & $100.0(2)$ & $100.0(2)$ \\
\hline 20 & $\begin{array}{c}\text { Sheer (6), } \\
\text { Catch, Noida }\end{array}$ & Curd & 6 & $6(100.0)$ & 00 \\
\hline \multirow{5}{*}{21} & \multirow{5}{*}{$\begin{array}{l}\text { Sudha(16), } \\
\text { Bihar }\end{array}$} & Curd & 4 & $2(50.0)$ & 00 \\
\hline & & Ice cream & 8 & $2(25.0)$ & 00 \\
\hline & & Cream & 2 & $0(0.0)$ & 00 \\
\hline & & Makhana Kheer & 2 & $0(0.0)$ & 00 \\
\hline & & Butter & 2 & $2(100.0)$ & 00 \\
\hline \multirow{2}{*}{22} & \multirow{2}{*}{$\begin{array}{c}\text { Vadilal (6), } \\
\text { Gujrat, Ahemdabad }\end{array}$} & Ice cream & 4 & $0(0.0)$ & 00 \\
\hline & & Matkakulfi & 2 & $0(0.0)$ & 00 \\
\hline & Total s & & 276 & $52.8(146)$ & $5.7(16)$ \\
\hline
\end{tabular}

None of the 6 milk products \{Cream (4), Coffee milkshakes (2), Fruit Yoghurt (2), Makhana Kheer (2), Rabdi (2)\} was positive in any of the six tests; ${ }^{(a)}$ Positives in at least one of 6 tests; ${ }^{(b)}$ IS 1311 PCR_REA

\subsection{Small sample size milk products}

\subsubsection{Lassi}

Out of $11.7 \%$ (20) lassi samples (six brands), 50.0\% (10) were positive (Table 2). Bio-presence was 25.0, 100.0, 100.0, and 100.0\% in samples from Mother dairy, Amul, Parag, and Sanchi dairies, respectively. None from Gopalji and Saras were positive (Table 4). i_FAT and microscopy were most sensitive $(40.0 \%)$ followed by d ELISA, LAT, and i ELISA (20.0\%). In IS900 PCR, none was positive. Except, $10.0 \%$ samples (positive in one test), rest $40.0 \%$ were detected by multiple tests (two to six tests) (Table 3 ).

\subsubsection{Butter}

In the case of butter, cumulatively, $12.5 \%$ and none samples were positive and negative respectively, in all six tests. Out of $9.6 \%$ (16) butter samples (four brands), $75.0 \%$ (12) were positive (Table 2) and bio-presence was $100.0 \%$ in Amul, Mother dairy, Saras, and Sudha brands (Table 4). i_FAT and microscopy were most sensitive $(87.5 \%)$ followed by d_ELISA $(75.5 \%)$, i_ELISA $(37.5 \%)$, LAT (25.0\%) and IS900 PCR (12.5\%). Except, $12.5 \%$ (positive in one test), rest $87.5 \%$ were positive by multiple tests (two to six tests) (Table 3). Screening of 16 positive samples in IS900 PCR, only two samples from Mother dairy were 'Indian Bison Type' (Table 4).

\subsubsection{Cheese and paneer}

Of the total, 6.5\% (10) cheese samples (four brands), four (40.0\%) were positive in multiple tests (i_FAT, microscopy, d_ELISA, and
LAT) (Tables 2 and 3) and bio-presence was 100.0\% in Amul brand, and samples from Mother dairy, Pankajpaneer and Saras) were negative (Table 4). i_ELISA and IS900 PCR detected 20.0\% samples. Bio-typing of four IS900 positive samples, $50.0 \%$ (2) from Amul were 'Indian Bison Type' (Table 4).

\subsubsection{Matkakulfi and other milk products}

Of four Matkakulfi (Cream well and Vadilal), two (Cream well) were positive by i_FAT and microscopy. Fruit yogurt (Mother dairy), cream (Amul), coffee milkshake (Cavins), Rabdi, and Makhana Kheer(Sudha) were negative (Tables 3 and 4).

\subsection{Screening by culture and IS900 Assay}

Of 276 milk products screened, $2.8 \%$ (lassi-1, ice-cream-1, butter2 , curd-2, and butter milk-2) were positive for live MAP bacilli. Culture positive milk products $(2.8 \%)$ were also detected positive by six tests except for one sample of lassi which was negative in IS900PCR. Further, among the $7.9 \%(22 / 276)$ milk products positive in IS900PCR, 6.0 (6/100), 13.8 (10/72), 4.76 (2/42), 12.5 $(2 / 16)$ and $20.0 \%(2 / 10)$ belonged to curd, butter-milk, ice cream, butter, and cheese, respectively (Table 2 ).

\subsection{Sensitivity and specificity of six tests}

Based on kappa and two-tailed $\mathrm{p}$ values, the sensitivity and specificity of each test were calculated and has been provided in Table 5. d_ELISA had highest (100.0\%) and IS900 PCR had lowest $(19.3 \%)$ sensitivity while IS900 PCR found to be most 
specific (100.0\%) and d_ELISA least specific (85.9\%). Based on a statistical comparison of six tests, the strength of agreement was 'good' for d_ELISA concerning i_ELISA, with a kappa value of 0.734. A comparison of LAT with i_ELISA showed the strength of agreement was 'very good' with a kappa value of 0.815 . Similarly, the strength of agreement was 'good' for i_FAT concerning microscopy with a kappa value of 0.700 (Table 5).

\subsection{Screening of IS900 assay negative samples by SYBR green Real Time assay}

Screening of 34 samples, \{negative in IS900PCR and positive in microscopy $(n-18)$, in i_FAT $(n-8)$ and d_ELISA $(n-8)\}, 20.6 \%$ (7/34) were positive using RT_PCR, which improved the detection rate of MAP infection in milk products (Table 6).

\section{Discussion}

India has $17.0 \%$ of the world's population of domestic livestock and JD is endemic in the country (Singh et al., 2014a; Gupta et al., 2019). Chaubey et al. (2017) in past 31 years (1985-2017) showed consistent increase in the bio-load from 11.4\% (464/4057) in 19851990 to $44.2 \%(3832 / 8658)$ in $2011-2017$, using multiple tests; $\{($ average $-26.8 \%(6976 / 26009)\}$. Studies further showed that biopresence increased from $44.2 \%$ (3832/8658) in 2011-2017 to $48.6 \%$ (5440/11180) in past nine months (April 2017-December 2017) (unpublished data). This is mainly due to low priority accorded to JD therefore there is absence of control measures. Though at 132.43 million tonnes of milk production (FAOSTAT, 2018), India is the leading milk producer in the world, however, per animal productivity is very low mainly due to the high bio-presence of MAP in the domestic livestock. Studies from Shankar et al. (2010) reported 22.0
- $100.0 \%$ bio-presence of MAP in milk products and $56.0-78.0 \%$ in ice-creams and flavored milk in 2010, Raghuvanshi et al. (2014) observed 0.0 to $16.6 \%$ in paneer samples from goat milk and Stephen et al. (2016) reported, $32.7-74.5 \%$ in paneer samples from bovine milk revealed high bio-presence of MAP in milk and milk products sold in India for human consumption.

The 276 milk products (12 types and 22 leading commercial brands) from Agra and Mathura were screened and seven (curd, buttermilk, ice cream, lassi, butter, cheese, and Matka kulfi) were positive for MAP. Milk products (cream, coffee milkshakes, fruit yogurt, makhana kheer, Rabdi) negative for MAP may be due to low sample size $(12 / 276$ or $4.3 \%)$ or required high temperature or long time heating (coffee milkshakes, makhana kheer, rabdi) during manufacturing. Makhana kheer a native porridge requires a long time boiling of milk. Rabdi is concentrated milk made by slow long time heating. Coffee milkshakes need boiling of milk. The cream is not boiled but in fruit yogurt, fruits are added to the cream.

In large sample-sized milk products, the highest samples were positive in curd $(66.0 \%)$, followed by buttermilk (50.5\%) and icecream $(28.5 \%)$, posing a serious threat to human health since products are of mass consumption. Human patients suffering from severe MAP infection had a weakness for ice-creams (Singh et al., 2016d). In small sample size products, the highest bio-presence was in butter (100.0\%), followed by lassi (50.5\%), Matka kulfi (50.0\%), and cheese $(40.0 \%)$. High bio-presence in milk products may be due to high bio-presence in domestic livestock (Singh et al., 2014a; Chaubey et al., 2017) and continue to increase (un-published data up to December 2017). A similar high bio-presence was reported in the human population of this region (Singh et al., 2014b), Study showed

Table 5 Sensitivity and specificity of diagnostic tests for the screening of commercial milk products $(n-276)$

\begin{tabular}{|c|c|c|c|c|c|c|c|}
\hline Tests type & Diagnostic test & Comparative test & $\begin{array}{l}\text { Two tailed } \mathrm{P} \\
\text { value }\end{array}$ & Kappa \pm SE & $\begin{array}{l}\text { Strength of } \\
\text { agreement }^{(b)}\end{array}$ & Sensitivity (\%) & Specificity (\%) \\
\hline \multirow{2}{*}{ Antibody based } & d_ELISA & \multirow{2}{*}{ i_ELISA } & 0.0003 & $0.734 \pm 0.063$ & Good & 100.0 & 85.9 \\
\hline & $\mathrm{LAT}^{(\mathrm{a})}$ & & 1.000 & $0.815 \pm 0.059$ & Very good & 87.1 & 95.3 \\
\hline \multirow{2}{*}{ Antigen based } & i_FAT ${ }^{(a)}$ & \multirow{2}{*}{ Microscopy } & 0.8231 & $0.700 \pm 0.062$ & Good & 80.7 & 88.8 \\
\hline & IS900 PCR & & $<0.0001$ & $0.219 \pm 0.059$ & Fair & 19.3 & 100.0 \\
\hline
\end{tabular}

${ }^{(a)}$ LAT- Latex Agglutination Test; i_FAT- Indirect Fluorescent Antibody Test; ${ }^{(b)}<0.20$ - poor; $0.21-0.40$ - fair; 0.41 - 0.60 - moderate; 0.61 - 0.80 substantial (good); and 0.81-1.00 - very good/almost perfect

Table 6 Comparative table of the presence of MAP bacilli in 34 milk products using Real Time IS900 PCR vis a vis microscopy, i FAT, traditional IS 900 PCR and d ELISA

\begin{tabular}{|c|c|c|c|c|c|}
\hline \multirow{2}{*}{ Species(n) } & \multicolumn{5}{|c|}{ Status of MAP; N (\%)(a) } \\
\hline & RT_PCR & Microscopy & i_FAT & IS900PCR & d_ELISA \\
\hline $\begin{array}{c}\text { Milk products }(\mathrm{n}= \\
34)\end{array}$ & $\begin{array}{c}20.6 \\
(7 / 34)\end{array}$ & $\begin{array}{c}52.9 \\
(18 / 34)\end{array}$ & $\begin{array}{c}23.5 \\
(8 / 34)\end{array}$ & 0.0 & $\begin{array}{c}23.5 \\
(8 / 34)\end{array}$ \\
\hline
\end{tabular}

${ }^{(a)}$ Figures in parenthesis are numbers; N- Positive samples in each test

Journal of Experimental Biology and Agricultural Sciences http://www.jebas.org 
milk products sold by leading market brands were 'unsafe' for human consumption. Of 23,196 human beings reported for screening at pathology laboratories in Mathura, $28.8 \%$ against auto-immune disorders, $40.5 \%$ infectious diseases, and $40.9 \%$ non-infectious disorders in 2013 (Singh et al., 2014b). Screening of 23196 patients by i_ELISA, MAP was active in $34.0 \%$ population (Singh et al., 2014b). Screening of 3093 blood by IS900 blood PCR, 8.4\% were positive for human paratuberculosis. These studies corroborated the high bio-presence of MAP in the human population as a consequence of the consumption of milk products contaminated with high bio-presence of MAP (Singh et al., 2014b).

Highest positivity was in butter $(100.0 \%)$, followed by curd (66.0\%), buttermilk (50.5\%), lassi (50.5\%), Matka kulfi (50.0\%), cheese $(40.0 \%)$ and ice-cream $(28.5 \%)$. Thick waxy wall of MAP bacilli has an affinity for fat molecules in butter, curd, lassi, buttermilk, and Matka kulfi (Mullan, 2015). Similarly, cheese $(40.0 \%)$ has high-fat contents, wherein bacilli get partitioned with fat. Though fat contents are high in ice-creams due to heating during making MAP bio-presence may be low. Of the milk products screened, butter was most unsafe for human consumption. In the absence of control programs, MAP bio-presence was high in domestic livestock (Singh et al., 2014a). This study first time revealed that consumption of milk products not safe, though the human population including babies (infant milk formula), largely depends on milk products as food items of mass consumption and are continuously getting exposed to MAP. Depending on stress conditions several cases are culminating as patients of 'human paratuberculosis'.

Test-wise, the sensitivity of i_FAT, microscopy, and d_ELISA was highest and parallel. i_FAT was most sensitive followed by microscopy and d_ELISA. i_ELISA and LAT had similar sensitivity in curd, buttermilk, ice-cream, and lassi. i_ELISA was superior for the screening of butter as compared to cheese, where LAT was better. The study highlighted the selection of a test for screening milk products after considering the nature of milk products. Depending on resources, purpose, and sample we can choose the screening test(s). The use of RT_PCR and culture led to further confirmation of MAP in milk products.

High bio-presence of MAP (28.5-100.0\%) in the milk products in present findings were similar to our earlier reports of high biopresence in domestic animals (Singh et al., 2014a) raw milk (personal communication) and commercial pasteurized liquid milk (Singh et al., 2018) and human population (Singh et al., 2014b) in North India. Unless MAP infection is controlled in animals, the human population will continue to get exposed to MAP. Chaubey et al. (2017) correlated that high bio-presence of MAP in the human population may have resulted in a sharp rise in autoimmune disorders (Crohn's disease, inflammatory bowel disease, ulcerative colitis, diabetes type 1 , thyroiditis, rheumatoid arthritis,
Allergic rhinitis, milk allergies, etc.). MAP infection is incurable both in animals and human beings.

Of the 12 types of milk products screened, consumption of butter, curd, buttermilk, lassi, and cheese was the most likely threat for human infection with MAP. Due to the presence of a thick waxy cell wall, MAP survives pasteurization temperatures by forming clumps (Donaghy et al., 2010). Viable MAP has been detected even after the application of pressure along with pasteurization (Donaghy et al., 2010). The available published reports provided evidence for the existence of live MAP in unpasteurized, pasteurized milk, colostrums, milk powder, and all types of fresh cheese by Bradner et al., (2013) and Eftekhari \& Mosavari, (2016).

Studies show high bio-presence of MAP in milk and milk products may be leading to the increased incidence of Crohn's disease in the human population. Botsaris et al. (2010) in their report on the biopresence of MAP DNA using quantitative real-time PCR (RT_PCR), showed that $25.0 \%$ cheese originating from sheep, goat, and mixed milk from farms and products in Cyprus were found positive. However, viable MAP bacilli were not detected either in the combined phage IS900 PCR or by conventional culture method. Faria et al. (2014) also reported MAP from 10.0 and $3.3 \%$ retail Coalho cheese samples in Brazil by PCR and culture, respectively, and sequenced the DNA from positive culture samples showing $99 \%$ identity with the insertion sequence IS 900 . Similarly, various researchers tested the efficacy of various tests in the detection of Mycobacterium avium paratuberculosis in milk products (Table 7). Using culture in the present study, live MAP colonies were recovered from $2.8 \%$ milk products (lassi, ice creams, butter, curd and butter, $0.3,0.3,0.7,0.7$ and $0.7 \%$, respectively).

Similar findings were reported by Van Brandt et al. (2011). The authors conducted a study to detect MAP in yogurt and commercial fermented milk products containing probiotic strains. They concluded the easy survivability of MAP in yogurt but MAP numbers decreased in fermented milk products containing probiotic cultures. Their results filled-up the knowledge gap on the behavior of MAP in yogurt and fermented milk products containing probiotic cultures. Though MAP could not be isolated from yogurt or fermented milk, their research was millstone and valuable in the context of the risk of MAP transmission to humans through yogurt and probiotic fermented milk products. Klanicova et al. (2012) and Cirone et al. (2013) confirmed the survival of MAP in fermented milk products (yogurt, acidophilus milk, and kefir) during fermentation conditions, low $\mathrm{pH}$ and refrigerated storage for at least 20 days. MAP in raw materials might reach consumers via consumption and emphasize on implementation of good manufacturing practices during the production and storage of fermented milk products. 
Table 7 Country-wise global bio-presence of Mycobacterium avium paratuberculosis in milk products

\begin{tabular}{|c|c|c|c|c|c|}
\hline Species & Countries & Sample type & Tests & Bio-presence (\%) & Reference \\
\hline \multirow{6}{*}{ Cattle } & \multirow{2}{*}{ Switzerland } & \multirow{2}{*}{ Semi-hard cheese } & PCR & 4.0 & \multirow{2}{*}{ Stephan et al. (2007) } \\
\hline & & & Culture & 0.0 & \\
\hline & \multirow{2}{*}{ USA } & Cheese & Culture & 23.0 & \multirow{2}{*}{$\begin{array}{l}\text { Clark Jr. et al. } \\
\qquad(2006)\end{array}$} \\
\hline & & Curd & PCR & 9.0 & \\
\hline & \multirow{2}{*}{ Brazil } & \multirow{2}{*}{ Cheese } & PCR & 10.0 & \multirow{2}{*}{ Faria et al. (2014) } \\
\hline & & & Culture & 3.3 & \\
\hline \multirow{5}{*}{ Goats and Sheep } & \multirow{5}{*}{ Czech Republic } & \multirow{2}{*}{ Hard cheese } & Culture & 5.4 & \multirow{4}{*}{$\begin{array}{l}\text { Ikonomopoulos et } \\
\text { al. (2005) }\end{array}$} \\
\hline & & & PCR & 5.4 & \\
\hline & & \multirow{2}{*}{ Semi-hard cheese } & Culture & 5.0 & \\
\hline & & & PCR & 50.0 & \\
\hline & & Cheese & PCR & 25.0 & Botsaris et al. (2010) \\
\hline
\end{tabular}

Singh \& Vihan (2004) screened raw milk of five goats suffering from clinical Johne's disease for the presence of MAP. Consistently high bio-presence of MAP in goat milk samples, authors concluded that MAP was endemic in goat herds located at CIRG, Makhdoom, India. This may be due to repeated transmission of MAP from infected mothers to the new generation through milk and colostrum. Despite regular screening and culling of suspected goats since the establishment of herds in 1979, the bio-presence of MAP could not be reduced and shedding MAP in feaces and milk continued. Screening of raw milk from a large number of goats, cows, and buffaloes the bio-presence was $9.4 \%$ in goats (Kumar et al., 2008), 6.0\% in cattle (Sharma et al., 2008) and $48.0 \%$ in buffaloes (Yadav et al., 2008). Shankar et al. (2010) in 2008 first time screened pasteurized milk and milk products and samples were centrifuged to concentrate MAP bacilli, which got partitioned in fat or sediment layers depending on fat percent. Each layer was processed independently. However, in this study milk products were screened without centrifugation.

The milk used in the preparation of these 12 milk products was mainly of bovine (buffaloes, cattle) origin and goat milk is sold as an adulterant. Therefore, the bio-presence of MAP estimated using milk products reflected the bio-presence of MAP in buffaloes and cattle and goats. After milk and ice-creams, soured milk products (curd, lassi, butter, and buttermilk) and fermented milk products (yogurt, cheese, and cream) were popular milk products. Curd, lassi, and buttermilk due to the presence of lactobacilliis prescribed for patients suffering from gastro-disorders and after antibiotic therapy. Mostly fresh curd is prepared in every home, however, in metropolitan cities, people depend on commercial curd, buttermilk, butter, and lassi. Mother dairy was the most popular brand sold in the capital city of New Delhi and Amul all over India.
Bio-typing of milk products (curd, butter-milk, ice-cream, lassi, butter, and cheese) revealed the presence of 'Indian Bison Type' biotype of MAP. It is predominant bio-type reported from animals, milk and milk products (raw and pasteurized), and human population and also wild animals and environment indicating circulation of the bacilli in the 'ecosystem' infecting new population (animals and human beings) and at the same time increasing in the percent bio-presence continuously (Singh et al., 2014a; Singh et al., 2014b; Chaubey et al., 2016; Singh et al., 2018).

\section{Conclusion}

The study indicated that the high bio-presence of MAP in milk products was a result of similar high bio-presence of MAP in raw milk used for making these milk products, which enabled MAP to survive heat treatments during pasteurization. High bio-presence of MAP and presence of live MAP bacilli in milk products suggested MAP as high-risk pathogen for the human population and exposure to MAP infection and fragments/components of bacilli. Test combinations were superior to individual tests for the screening of milk products and test combinations can be decided depending on the type of sample, the number of bacilli, purpose study, resources available, etc. In-order to prevent transmission of MAP to the next generation of animals and human population control measures are urgently needed. To prevent the infection of farm animals will lead to a reduction in chances of contamination of milk and milk products, which may lead to infection of the human population. Milk products sold by leading market brands were un-safe for human use. Brands negative in this study may not be a true picture since the sample size was very low in the number of milk products, therefore the need for large scale study encompassing all the regions of the country. 


\section{Acknowledgement}

Authors are thankful to Indian Council of Medical Research (ICMR) (grant No. 5/8/5/28/TF/2013/ECD-I) and Ministry of Food Processing Industries (MoFPI), New Delhi (Grant No. SERB/MOFPI/0029/2014) for providing funds and Director, Central Institute for Research on Goats, Makhdoom, Farah for providing laboratory facilities.

\section{Conflict Of Interest}

No potential conflict of interest to declare.

\section{References}

Acharya KR, Dhand NK, Whittington RJ, Plain KM (2017) Detection of Mycobacterium avium subspecies paratuberculosis in powdered infant formula using IS 900 quantitative PCR and liquid culture media. International Journal of Food Microbiology 257: 19. doi:10.1016/j.ijfoodmicro.2017.06.005.

Banche G, Allizond V, Sostegni R, Lavagna A, Bergallo M, Sidoti F, Daperno M, Rocca R, Cuffini AM (2015) Application of multiple laboratory tests for Mycobacterium avium ssp. paratuberculosis detection in Crohn's disease patient specimens. New Microbiologica 38(3): 357-367.

Bhattarai B, Fosgate GT, Osterstock JB, Fossler CP, Park SC, Roussel AJ (2013) Comparison of calf weaning weight and associated economic variables between beef cows with and without serum antibodies against or isolation from feces of Mycobacterium avium subsp paratuberculosis. Journal of the American Veterinary Medical Association 243(11): 1609-1615. doi:10.2460/javma.243.11.1609.

Botsaris G, Slana I, Liapi M, Dodd C, Economides C, Rees C, Pavlik I (2010) Rapid detection methods for viable Mycobacterium avium subspecies paratuberculosis in milk and cheese. International Journal of Food Microbiology 141: S87-S90. doi:10.1016/j.ijfoodmicro.2010.03.016.

Botsaris G, Swift BMC, Slana I, Liapi M, Christodoulou M, Hatzitofi M, Christodoulou V, Rees CED (2016) Detection of viable Mycobacterium avium subspecies paratuberculosis in powdered infant formula by phage-PCR and confirmed by culture. International Journal of Food Microbiology 216: 91-94. doi:10.1016/j.ijfoodmicro.2015.09.011.

Bradner LK, Stabel JR, Beitz DC, Robbe-Austerman S (2013) Shedding of Mycobacterium avium subsp. paratuberculosis into milk and colostrum of naturally infected dairy cows over complete lactation cycles. Animal Industry Report AS 659, ASL R2793, 3 pp. Available at: https://lib.dr.iastate.edu/ans_air/vol659/iss1/44 accessed on 12 July 2018.
Chaubey KK, Gupta RD, Gupta S, Singh SV, Bhatia AK, Jayaraman S, Kumar N, Goel A, Rathore AS, Sahzad, Sohal JS, Stephen BJ, Singh M, Goyal M, Dhama K, Derakhshandeh A (2016) Trends and advances in the diagnosis and control of paratuberculosis in domestic livestock. Veterinary Quarterly 36(4): 203-227. doi:10.1080/01652176.2016.1196508.

Chaubey KK, Singh SV, Gupta S, Singh M, Sohal JS, Kumar N, Singh MK, Bhatia AK, Dhama K (2017) Mycobacterium avium subspecies paratuberculosis-an important food borne pathogen of high public health significance with special reference to India: an update. Veterinary Quarterly 37(1): 282-299. doi:10.1080/01652176.2017.1397301.

Cho J, Tauer LW, Schukken YH, Gomez MI, Smith RL, Lu Z, Grohn YT (2012) Economic analysis of Mycobacterium avium subspecies paratuberculosis vaccines in dairy herds. Journal of Dairy Science 95(4): 1855-1872. doi:10.3168/jds.2011-4787.

Cirone K, Huberman Y, Morsella C, Méndez L, Jorge M, Paolicchi F (2013) Growth of Mycobacterium avium subsp. paratuberculosis, Escherichia coli, and Salmonella Enteritidis during preparation and storage of yogurt. ISRN Microbiology 2013, Article ID 247018, 7 pp. doi:10.1155/2013/247018.

Collins MT (2002) Interpretation of a commercial bovine paratuberculosis enzyme-linked immunosorbent assay by using likelihood ratios. Clinical and Diagnostic Laboratory Immunology 9(6): 1367-1371.

D’Haese I, Dumon H, Werbrouck V, De Jonghe, Herman L (2005) Improved detection of Mycobacterium paratuberculosis in milk. Journal of Dairy Research 72: 125-128.

Donaghy JA, Johnson J, Rowe MT (2010) Detection of Mycobacterium avium ssp. paratuberculosis in cheese, milk powder and milk using IS900 and f57-based qPCR assays. Journal of Applied Microbiology 110(2): 479-489. doi:10.1111/j.13652672.2010.04905.

Eftekhari M, Mosavari N (2016) Isolation and molecular identification of Mycobacterium paratuberculosis from commercially available pasteurized milk and raw milk samples collected from two infected cattle farms in Alborz Province. Iran. International Journal of Mycobacteriology 5(1): S222S223.doi:10.1016/j.ijmyco.2016.10.005.

FAOSTAT (2018) Food and Agriculture Organization of the United Nations. http://www.fao.org/faostat/en/\#data/QA

Faria AC, Schwarz DG, Carvalho IA, Rocha BB, Castro KD, Silva MR, Moreira MA (2014) Viable Mycobacterium avium subspecies paratuberculosis in retail artisanal Coalho cheese from Northeastern Brazil. Journal of Dairy Science 97(7): 4111-4114. doi:10.3168/jds.2013-7835. 
Geraghty T, Graham DA, Mullowney P, More SJ (2014) A review of bovine Johne's disease control activities in 6 endemically infected countries. Preventive Veterinary Medicine 116(1-2): 1-11. doi:10.1016/j.prevetmed.2014.06.003.

Grant I (2006) Occurrence of Mycobacterium avium subsp paratuberculosis in foods and the impact of milk processing on its survival. In 8th International colloquium on paratuberculosis, Copenhague, Denmark Pp. 276. Available on www.paratuberculosis.info/web/images/stories/pdfs/148 Access on 18th April, 2018.

Gupta S, Singh SV, Gururaj K, Chaubey KK, Singh M, Lahiri B, Agarwal P, Kumar A, Misri J, Sohal JS, Hemati Z, Bhatia AK (2017) Comparative evaluation of traditional IS900 PCR assay with newer assays ('Taqman probe PCR' and 'SYBR green Real time PCR') in thyroid disorder patientssero-positive for Mycobacterium avium subspecies paratuberculosis using Indigenous ELISA kit Indian Journal of Biotechnology 16(1): 228-234.

Gupta S, Singh SV, Singh M, Chaubey KK, Karthik K, Bhatia AK, Kumar N, Dhama K (2019) Vaccine approaches for the 'therapeutic management' of Mycobacterium avium subspecies paratuberculosis infection in domestic livestock. Veterinary Quarterly 39(1): 143-152. doi: 10.1080/01652176.2019.1667042.

Hammer P, Kiesner C, Walte HG, Teufel P (2006) Inactivation of Mycobacterium avium subsp. Paratuberculosis in whole milk, skim milk and cream in a pilot plant pasteurizer. Kieler Milchwirtschaftliche Forschungsberichte 58(1): 17-40.

Hruska K, Slana I, Kralik P, Pavlik I (2011) Mycobacterium avium subsp. Paratuberculosis in powdered infant milk: F57 competitive realtime PCR. Veterinarni Medicina 56(5): 226-230.

Ikonomopoulos J, Pavlik I, Bartos M, Svastova P, Ayele WY, Roubal P, Lukas J, Cook N, Gazouli M (2005) Detection of Mycobacterium avium subsp. paratuberculosis in Retail Cheeses from Greece and the Czech Republic. Applied and Environmental Microbiology 71:8934-8936.

Johnson-Ifearulundu Y, Kaneene JB, Lloyd JW (1999) Herdlevel economic analysis of the impact of paratuberculosis on dairy herds. Journal of the American Veterinary Medical Association 214(6): 822-825.

Klanicova B, Slana I, Roubal P, Pavlik I, Kralik P (2012) Mycobacterium avium subsp. paratuberculosis survival during fermentation of soured milk products detected by culture and quantitative real time PCR methods. International Journal of Food Microbiology 157(2): 150-155. doi:10.1016/j.ijfoodmicro.2012.04.021.

Kumar S, Singh SV, Sevilla I, Singh AV, Whittington RJ, Juste RA, Sharma G, Singh PK, Sohal JS (2008) Lacto-prevalence, genotyping of Mycobacterium avium subspecies paratuberculosis and evaluation of three diagnostic tests in milk of naturally infected goatherds. Small Ruminant Research 74(1-3): 37-44. doi:10.1016/j.smallrumres.2007.03.005.

Merkal RS, Richards WD (1972) Inhibition of fungal growth in the cultural isolation of mycobacteria. Applied Microbiology 24(2): 205-207.

Messelhäusser U, Kampf P, Hormansdorfer S, Wagner B, Schalch B, Busch U, Holler C, Wallner P, Barth G, Rampp A (2012) Culture and molecular method for detection of Mycobacterium tuberculosis complex and Mycobacterium avium subsp. paratuberculosis in milk and dairy products. Applied and Environmental Microbiology 78(1): 295-297. doi:10.1128/AEM.06322-11.

Mullan WMA (2015) Modelling the lethal effects of HTST pasteurization. Is it time to raise statutory time/temperature conditions to destroy Mycobacterium avium subsp. paratuberculosis (MAP)? Dairy Science and Food Technology 7 pp. Available at: https://www.dairyscience.info/index.php/food-model/277-htst-

pasteurization.html?tmpl=component\&print $=1 \&$ layout=default accessed on 12 July 2018).

Naser SA, Sagramsingh SR, Naser AS, Thanigachalam S (2014) Mycobacterium avium subspecies paratuberculosis causes Crohn's disease in some inflammatory bowel disease patients. World Journal of Gastroenterology 20(23): 7403-7415. doi:10.3748/wjg.v20.i23.7403.

Raghuvanshi TS, Sharma RB, Singh AV, Singh B, Singh SV, Dhama K (2010) 'Indigenous milk ELISA kit' vis a vis multiple test regime for the estimation of lacto-prevalence of Mycobacterium avium subspecies paratuberculosis in goatherds endemic for Johne's disease. Indian Journal of Comparative Microbiology Immunology and Infections Diseases 31(1-2): 41-43.

Raghuvanshi TS, Singh SV, Sharma RB, Gupta S, Chaubey KK, Kumar N, Dhama K (2014) A pilot study on the presence of Mycobacterium avium subspecies paratuberculosis in fresh cheese (paneer) prepared from goat milk of herds endemic for Johne's disease. Journal of Infection and Molecular Biology 1: 46-48.

Raizman EA, Fetrow JP, Wells SJ (2009) Loss of income from cows shedding Mycobacterium avium subspecies paratuberculosis prior to calving compared with cows not shedding the organism on two Minnesota dairy farms. Journal of Dairy Science 92(10): 49294936. doi:10.3168/jds.2009-2133.

Sevilla I, Singh SV, Garrido JM, Aduriz G, Rodriguez S, Geijo MV, Juste RA (2005) Molecular typing of Mycobacterium avium subspecies paratuberculosis strains from different hosts and regions. Scientific and Technical Review of the Office International des Epizooties 24(3): 1061-1066. doi:10.20506/rst.24.3.1634. 
Shankar H, Singh SV, Singh PK, Singh AV, Sohal JS, Greenstein RJ (2010) Presence, characterization and genotype profiles of Mycobacterium avium subspecies paratuberculosis from unpasteurized individual and pooled milk, commercial pasteurized milk, and milk products in India by culture, PCR, and PCR-REA methods. International Journal of Infectious Diseases 14(2): 121126. doi:10.1016/j.ijid.2009.03.031

Sharma G, Singh SV, Sevilla I, Singh AV, Whittington RJ, Juste RA, Vihan VS (2008) Evaluation of indigenous milk ELISA with $\mathrm{m}$-culture and m-PCR for the diagnosis of Bovine Johne's disease (BJD) in lactating Indian dairy cattle. Research in Veterinary Science $\quad 84(1): \quad 30-37 . \quad \mathrm{ftp} / / / \mathrm{s} 173-183-201-$ 52.ab.hsia.telus.net/AgroMediaDocs/JDrefs/ RVS84_30.pdf.

Shephard RW, Williams SH, Beckett SD (2016) Farm economic impacts of bovine Johne's disease in endemically infected Australian dairy herds. Australian Veterinary Journal 94(7): 232239. doi:10.1111/avj.12455.

Singh AV, Singh SV, Makharia GK, Singh PK, Sohal JS (2008) Presence and characterization of Mycobacterium avium subspecies paratuberculosis from clinical and suspected cases of Crohn's disease and in the healthy human population in India. International Journal of Infectious Diseases 12(2): 190-197.

Singh M, Gupta S, Singh SV, Chaubey KK, Sohal JS, Dhama K (2018) Bio-incidence of Mycobacterium avium subspecies paratuberculosis in the pasteurized liquid milk, flavoured milk and milk powder commercially sold by leading market brands in India. Journal of Experimental Biology and Agricultural Sciences 6(1): 188-203. doi:10.18006/2018.6(1).188.203.

Singh SV, Kuenstner JT, Davis WC, Agarwal P, Kumar N, Singh D, Gupta S, Chaubey KK, Kumar A, Misri J, Jayaraman S, Sohal JS, Dhama K (2016d) Concurrent resolution of chronic diarrhea likely due to Crohn's disease and infection with Mycobacterium avium paratuberculosis. Frontier in Medicine 3:49, 5 pp. doi:10.3389/fmed.2016.00049.

Singh SV, Kumar N, Sohal JS, Singh AV, Singh PK, Agrawal ND, Gupta S, Chaubey KK, Deb R, Dhama K, Rawat KD (2014b) First mass screening of the human population to estimate the biopresence of Mycobacterium avium subspecies paratuberculosis in North India. Journal of Public Health and Epidemiology 6(1): 20 29. doi:10.5897/JPHE2013.0564.

Singh SV, Singh AV, Singh R, Sandhu KS, Singh PK, Sohal JS, Gupta VK, Vihan VS (2007) Evaluation of highly sensitive indigenous milk ELISA kit with faecal culture, milk culture and faecal-PCR for the diagnosis of bovine Johne's disease (BJD) in India. Comparative Immunology, Microbiology and Infectious Diseases 30(3): 175-186. doi:10.1016/j.cimid.2006.12.002.
Singh SV, Singh PK, Singh AV, Sohal JS, Kumar N (2014a) Biopresence and bio-type profiles of Mycobacterium avium subspecies paratuberculosis infection in the domestic livestock population endemic for Johne's disease: A survey of 28 years (1985-2013) in India. Transboundary and Emerging Diseases 61(1): 43-55. doi:10.1111/tbed.12216

Singh SV, Sohal JS, Singh PK, Singh AV (2009) Genotype profiles of Mycobacterium avium subspecies paratuberculosis isolates recovered from animals, commercial milk, and human beings in North India. International Journal of Infectious Diseases 13(5): 221-227. doi:10.1016/j.ijid.2008.

Singh SV, Stephen BJ, Singh M, Gupta S, Chaubey KK, Sahzad, Jayaraman S, Aseri GK, Sohal JS, Bhatia AK, Chauhan J, Dhama K (2016a) Evaluation of milk dot-ELISA as field based test vis a vis milk plate ELISA for the detection of Mycobacterium avium subspecies paratuberculosis (MAP) in lactating domestic livestock. Indian Journal of Biotechnology 15(2): 166-171.

Singh SV, Stephen BJ, Singh M, Gupta S, Chaubey KK, Sahzad, Jayaraman S, Sachan TK, Aseri GK, Jain M, Sohal JS, Dhama K (2016b) Evaluation of Indirect Fluorescent Antibody Test (i_FAT) as the 'mass screening test' for the diagnosis of Mycobacterium avium subspecies paratuberculosis infection in the milk samples of lactating domestic livestock. Journal of Experimental Biology and Agricultural Sciences 4(5): 533-540. doi:10.18006/2016.4(5).533.540.

Singh SV, Stephen BJ, Singh M, Gupta S, Chaubey KK, Sahzad, Jayaraman S, Sachan TK, Sohal JS, Dhama K, Mukartal SY, Hemati Z (2016c) Comparison of newly standardized 'Latex milk agglutination test', with 'Indigenous milk ELISA' for 'on spot' screening of domestic livestock against Mycobacterium avium subsp. paratuberculosis infection. Indian Journal of Biotechnology 15(4): 511-517.

Singh SV, Vihan V (2004) Detection of Mycobacterium avium subsp. paratuberculosis in goat milk. Small Ruminant Research 54(3): 231-235. doi:10.1016/j.smallrumres.2003.12.002.

Stephan R, Schumacher S, Tasara T, Grant IR (2007) Prevalence of Mycobacterium avium Subspecies paratuberculosis in Swiss Raw Milk Cheeses Collected at the Retail Level Journal of Dairy Science 90:3590-3595. doi:10.3168/jds.2007-0015.

Stephen BJ, Singh M, Singh SV, Gupta S, Chaubey KK, Sahzad, Jayaraman S, Jain M, SohalJS, Mukartal SY, Dhama K (2016) Biocontamination' estimates of Mycobacterium avium subspecies paratuberculosis in fresh cottage cheese (Paneer) sold in rural, semiurban and peri-urban regions of South Uttar Pradesh using multiple diagnostic tests. Advances in Animal and Veterinary Sciences 4(8): 441-448. doi:10.14737/journal.aavs/2016/4.8.441.448. 
Van Brandt L, Coudijzer K, Herman L, Michiels C, Hendrickx M, Vlaemynck G (2011) Survival of Mycobacterium avium ssp. paratuberculosis in yoghurt and in commercial fermented milk products containing probiotic cultures. Journal of Applied Microbiology 110(5): 1252-1261. doi:10.1111/j.13652672.2011.04979.x.

vanSoolingen D, Hermans PW, de Haas PE, Soll DR, van Embden JD (1991) Occurrence and stability of insertion sequences in Mycobacterium tuberculosis complex strains: evaluation of an insertion sequence-dependent DNA polymorphism as a tool in the epidemiology of tuberculosis. Journal of Clinical Microbiology 29(11): 2578-2586.
Vary PH, Andersen PR, Green E, Hermon-Taylor J,McFadden J (1990) Use of highly specific DNA probes and the polymerase chain reaction to detect Mycobacterium paratuberculosis in Johne's disease. Journal of Clinical Microbiology 28(5): 933-937.

Whittington RJ, Windsor PA (2009) In utero infection of cattle with Mycobacterium avium subsp. paratuberculosis: a critical review and meta-analysis. The Veterinarians J.179(1): 60-69. doi:10.1016/j.tvj1.2007.08.023.

Yadav D, Singh SV, Singh AV, Sevilla I, Juste RA, Singh PK, Sohal JS (2008) Pathogenic 'Bison-type' Mycobacterium avium subsp. Paratuberculosis genotype characterized from riverine buffalo (Bubalus bubalis) in North India. Indian Journal of Comparative Microbiology Immunology and Infections Diseases 31(4): 373-387. doi:10.1016/j.cimid.2007.06.007.

Journal of Experimental Biology and Agricultural Sciences http://www.jebas.org 